\title{
Clinicopathological studies of gastrointestinal tract disorders in sheep with parasitic infection
}

\author{
Sarvan Kumar ${ }^{1}$, K. K. Jakhar ${ }^{1}$, Satyavir Singh², Sandeep Potliya ${ }^{3}$, Kailash Kumar ${ }^{4}$ and Madan Pal ${ }^{3}$
}

1. Department of Veterinary Pathology, Lala Lajpat Rai University of Veterinary \& Animal Sciences, Hisar, Haryana, India; 2. Department of Veterinary Parasitology, Lala Lajpat Rai University of Veterinary \& Animal Sciences, Hisar, Haryana, India; 3. Department of Veterinary Surgery and Radiology, Lala Lajpat Rai University of Veterinary \& Animal Sciences, Hisar, Haryana, India; 4. Department of Veterinary Gynaecology and Obstetrics, Lala Lajpat Rai University of Veterinary \& Animal Sciences, Hisar, Haryana, India.

Corresponding author: Sarvan Kumar, email: drsrvn38@gmail.com,KKJ: hod.vpp@llruvas.edu.in, SS: satyavirgrewal@gmail.com, SP: sandeeppotliya@gmail.com,

KK: dr.kailashbishnoi@gmail.com, MP: drmadanlega@gmail.com

Received: 03-09-2014, Revised: 27-11-2014, Accepted: 02-12-2014, Published: 09-01-2015

doi: 10.14202/vetworld.2015.29-32. How to cite this article: Kumar S, Jakhar KK, Singh S, Potliya S, Kumar K, Pal M (2015) Clinico-pathological studies of gastrointestinal tract disorders in sheep with parasitic infection, Veterinary World 8(1): 29-32.

\begin{abstract}
Aim: This study was envisaged to elucidate the parasitological aspects of gastrointestinal tract (GIT) disorders of sheep.

Materials and Methods: Fecal, blood and serum samples collected from 31 sheep/lambs of Sheep Breeding Farm, Lala Lajpat Rai University of Veterinary \& Animal Sciences, Hisar.

Results: Of 25 cases, strongyle eggs (12 cases, 48\%) were a major infection, followed by Strongyloides spp. (8 cases, $32 \%$ ) and Moniezia spp. (5 case, 20\%). In one case, massive infection of strongyle particularly Haemonchus contortus and Moniezia spp. was observed. All these animals were found negative for hemoprotozoan parasites in blood smear examination. Hematological studies revealed that significantly decreased values of hemoglobin (Hb), packed cell volume (PCV) and total erythrocytic count (TEC). Absolute leukocytic count revealed significant leukocytosis due to neutrophilia, lymphocytosis, monocytosis and eosinophilia. Serum biochemical profiles of diarrheic sheep/lambs in present study were significant decrease in values of total protein, serum globulin, glucose where as significant increase in the albumin: Globulin ratio, aspartate aminotransaminase (AST), alanine aminotransaminase (ALT), alkaline phosphatise (ALKP) and bilirubin.
\end{abstract}

Conclusions: From the present study, it is reasonable to conclude that major parasitic infection of sheep/lamb observed was strongyle, followed by Strongyloides spp. and Moniezia spp. Hemato-biochemical studies revealed significant leukocytosis and increase in AST, ALT, ALKP and bilirubin.

Keywords: clinico-pathology, gastrointestinal tract disorders, parasitic infection, sheep.

\section{Introduction}

Agriculture is the mainstay of Indian economy, where in agriculture and allied sector like, livestock, dairying and fisheries contribute about $15.18 \%$ of Gross Domestic Product [1]. Contribution of livestock sector to the food basket in the form of milk, egg and meat is of significance in fulfilling of animal protein requirement of ever and fast growing human population. In rural India where over $15-20 \%$ families are landless and about $80 \%$ of the land holders belong to the category of small and marginal farmers, livestock is the main source of livelihood. In the absence of fertile lands and assured irrigation which are controlled by a small population of rich farmers and lack of employment in the industrial and service sectors, most of the rural families belonging to socio-economically weaker sections of the society maintain different species of livestock to supplement their income. Although the landowners prefer cattle and buffaloes, the landless prefer to own sheep, goat and poultry. With the policy

Copyright: The authors. This article is an open access article licensed under the terms of the Creative Commons Attributin License (http:// creative commons.org/licenses/by/2.0) which permits unrestricted use, distribution and reproduction in any medium, provided the work is properly cited. of the State Animal Husbandry Department to extend free breeding, vaccination and veterinary services and permit free grazing on community lands, the farmers were encouraged to expand their herd size without any major financial burden [2]. This has probably been the reason for the presence of the world's largest livestock population in India. India ranks second in sheep population (71.56 million) in the world [3]. Of this 0.63 million sheep account from Haryana [4]. Although safe and effective treatment and control methods exist for the most internal and external parasites, many animals continue to suffer from preventable parasitic infections. Geographical location, housing conditions and species play a role in which parasites are likely to be a problem. Internal and external parasites can cause great discomfort, transmit disease to animals and significantly interfere with the growth and performance of animals.

Hematology and serum biochemistry of infected animals is very sensitive indicators for the degree of hepatic damage and the parasitic infection severity, in which liver damage upsets the vital metabolic processes for normal health and optimum productivity of the animal. 
The purpose of this study was to overview the correlation between clinicopathology in the gastrointestinal tract (GIT) disorders due to some parasitic infection and its effect on hematology and clinical biochemistry in sheep.

\section{Materials and Methods}

\section{Ethical approval}

The study was conducted after the approval of the Institutional Animal Ethics Committee.

\section{Collection of sample}

Proposed study was conducted on 31 sheep/ lambs including 6 healthy and 25 diseased sheep/ lambs affected with GIT disorders. Samples of feces, blood and serum for research was collected from Sheep Breeding Farm, Lala Lajpat Rai University of Veterinary \& Animal Sciences, Hisar.

\section{Faecal examination for parasitic eggs and ova}

Fecal samples were collected directly from the rectum from clinical cases of sheep/lamb having GIT disorders. These fecal samples were examined for the presence of helminthic ova, both heavy and light, and coccidial oocysts. For examination, floatation and sedimentation methods were employed [5].

\section{Hematological examination}

Hematological studies viz., Hb, TLC, differential leukocytic count, TEC, PCV, erythrocytic sedimentation rate (ESR), mean corpuscular volume (MCV), mean corpuscular $\mathrm{Hb}$ and mean corpuscular $\mathrm{Hb}$ concentration (MCHC) were estimated following the method of Benjamin [6] within the $6 \mathrm{~h}$ of blood collection.

\section{Serum biochemical examination}

Serum biochemical parameters were determined by using Technicon Ames RA-50 chemistry analyzer using diagnostic kits of Bayer [7]. The levels of the following plasma constituents were determined: Total protein (TP), albumin, total bilirubin and enzyme activities of alkaline phosphatase (ALKP), alanine aminotransferase (ALT) and aspartate aminotransferase (AST). The gamma-globulin levels were also measured and the albumin: Globulin ratio was calculated.

\section{Statistical analysis}

The Student's t-test using SPSS statistics 17.0 software (IBM Corporation, New York, USA) was applied to statistically analyze the results obtained with different study groups.

\section{Results}

The results of parasitic findings in 31 cases (6 healthy animals and 25 animals showing GIT disorders) of sheep/lambs are; maximum infection was in sheep of age group 2-5 months and least in age group of $>1$ year. Out of 25 cases, strongyle eggs (12 cases, 48\%) was a major infection, followed by Strongyloides spp. (8 cases, 32\%) and Moniezia spp. ( 5 case, 20\%), respectively. In one case, mixed massive infection of strongyle particularly Haemonchus contortus, strongyloides spp. and Moniezia spp. were observed. All these animals were found negative for hemoprotozoan parasites in blood smear examination. Hematological studies of blood collected from diarrheic sheep/lambs revealed significantly $(\mathrm{p} \leq 0.05)$ decreased values of $\mathrm{Hb}(8.184 \pm 0.194), \mathrm{PCV}$ $(30.40 \pm 1.146)$ and TEC (8.22 \pm 0.249$)$. Absolute leukocytic count revealed significant $(\mathrm{p} \leq 0.05)$ leukocytosis $(19.156 \pm 1.443)$ due to neutrophilia, lymphocytosis, monocytosis and eosinophilia. No effect was seen on ESR $(0.14 \pm 0.004)$. An analysis of erythrocytic indices revealed no significant change in MCV (36.89 \pm 0.719$)$, mean corpuscular $\mathrm{Hb}(10.22 \pm 0.463)$ and MCHC (27.37 \pm 0.587$)$ as shown in Figure-1.

Serum biochemical profiles of diarrheic sheep/ lambs in present study showed significant $(\mathrm{p} \leq 0.05)$ decrease in values of TP $(4.76 \pm 0.118)$, serum globulin $(1.66 \pm 0.12030)$ and serum glucose $(56.26 \pm 1.725)$ whereas significant $(\mathrm{p} \leq 0.05)$ increase in the albumin: globulin ratio $(2.46 \pm 0.29345)$. The activity of AST (211.6 \pm 13.92$)$, ALT $(63.34 \pm 1.54)$ and ALKP $(154.28 \pm 19.662)$ and total bilirubin $(0.107 \pm 0.0077)$ were significantly $(\mathrm{p} \leq 0.05)$ increased in diarrheic sheep/lambs shown in Figures-2a and b. There was no significant difference in hemato-biochemical studies among age group.

\section{Discussion}

Examination of intestinal contents/feces for parasitic isolation revealed maximum infection was in sheep of age group 2-5 months and least in age group of $>1$ year $[8,9]$. Mixed parasitic findings revealed maximum cases of mixed infection of strongyle and Strongyloides spp. and only one case of mixed infection of strongyle, Strongyloides spp. and Moniezia spp. These findings were in general, agreement with those reported by Mederos et al. and Lashari and Tasawar $[10,11]$. Prevailing agro-climatic conditions like overstocking of the animals, grazing of young and adult animals together with poorly drained land provide an ideal condition for the transmission of the endoparasites to build up clinical infection of the host. The overall higher incidence of nematodes infection in the areas surveyed could be attributed to lower

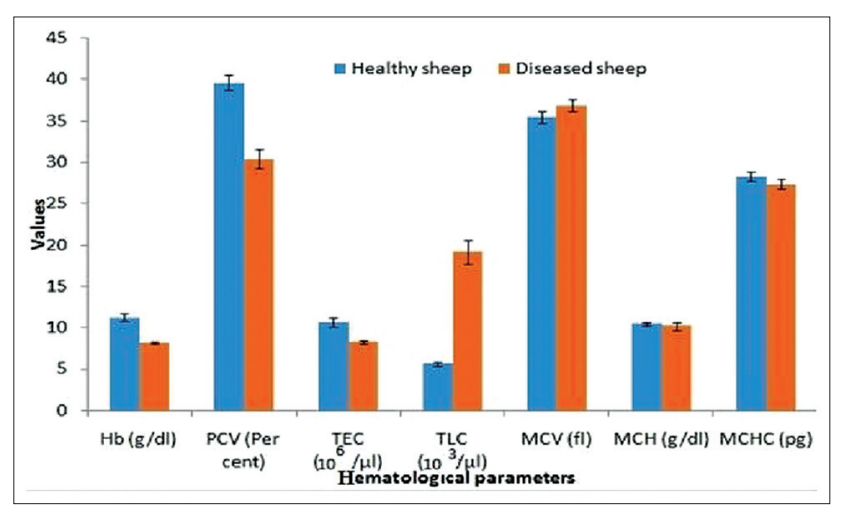

Figure-1: Histograms representing hematological parameters of healthy and diseased sheep. 


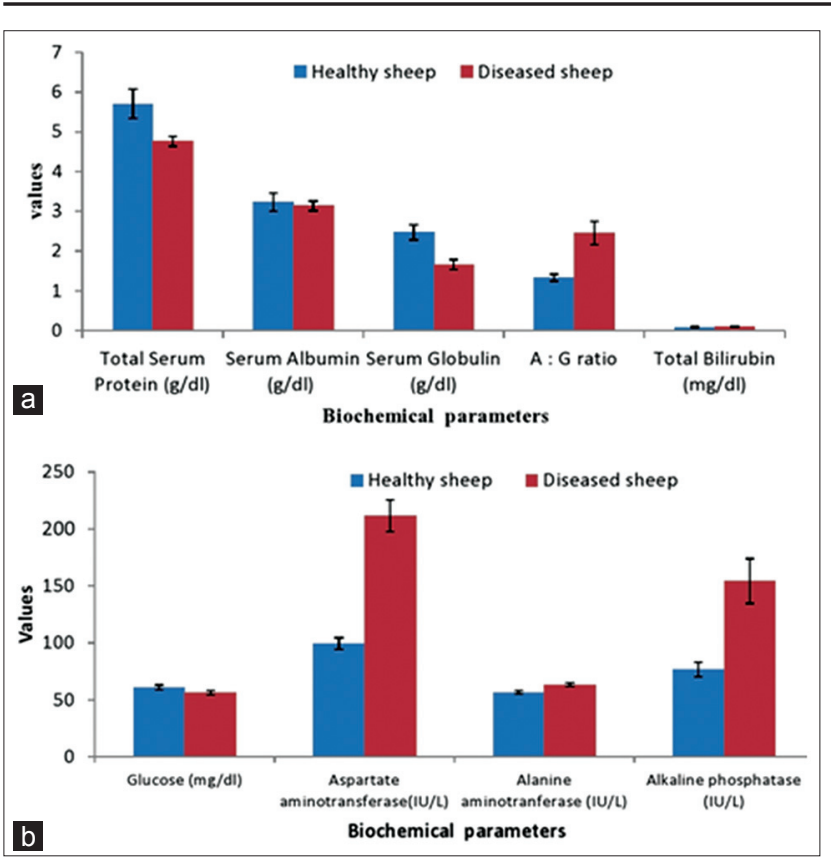

Figure-2: (a,b)Histograms representing serum biochemical parameters of healthy and diseased sheep.

immunity of hosts as a result of malnutrition. All the livestock in the area under investigation largely depended on grazing in deteriorated range-lands [12].

Hematological studies of blood collected from diarrheic sheep/lambs revealed significantly decreased values of $\mathrm{Hb}, \mathrm{PCV}$ and TEC. Amongst GI helminths of sheep. H. contortus is the predominant species. Main pathological lesion caused by $H$. contortus infection is anemia. Both adult and fourth stage larvae suck blood and in addition, migration of adult and larvae cause hemorrhages into the abomasum. The average blood loss due to H. contortus infection is $0.03 \mathrm{ml} /$ parasite/day [13]. The hematological studies in present investigations were in unison with the observation of Dhanlakshmi et al. [14], Zaki et al. [15] and Purohit et al. [16].

Absolute leukocytic count revealed significant leukocytosis due to neutrophilia, lymphocytosis, monocytosis and eosinophilia were in agreement with the observation of Misra et al. [17]. The decrease in value of $\mathrm{Hb}, \mathrm{PCV}$ and TEC might be due to the presence of strongyle infection, which had been recognized as active blood sucker in stomach and intestine and also been observed in present studies.

Serum biochemical profiles of diarrheic sheep/ lambs in the present study were significant decrease in values of TP, serum globulin and serum glucose whereas significant increase in the albumin: globulin ratio. These results are in consonance with finding of Maiti et al. [18], Pandit et al. [19], Dhanlakshmi et al. [14] Purohit et al. [16], Bordoloi et al. [13] and Qamar and Maqbool [20]. Inappetance with the resultant reduction in dietary protein, malabsorption and plasma losses from damaged intestinal mucosa might be the main cause for marked hypoproteinemia. The inflammation of the intestine by development stages of parasites might also due to poor absorption of protein metabolites resulting low level of TP and massive ascites since ascetic fluid contains a large amount of protein $[13,14]$. Low serum glucose in the diarrheic sheep/lambs might be due to decreased appetite of animals, decreased absorption into the blood stream and rapid absorption and utilization of soluble carbohydrate and lipids from the gut by parasites [21].

The activity of aspartate aminotransferase, alanine aminotransferase and alkaline phosphatase and increased total bilirubin were significantly increased in diarrheic sheep/lambs. Specific hepatic function are greatly affected by a wide variety of the pathological condition of extrahepatic origin specially GIT origin. Similar finding were also reported by Prasanthi et al. [22], Zaki et al. [15] and Bordoloi et al. [13]. Since these enzymes have their function and greatest concentration within the cell increase in enzymatic activities reflect cellular abnormalities which directly related to damage that has occurred to hepatocytes, pathological lesions of intestine and cardiac infarction [16] which were also be evidenced in presented studies. As alkaline phosphatase is widely distributed in the body and found in high concentration in bone (in oestoblast), intestinal mucosa, renal tubules cell, liver and placenta; increase in the alkaline phosphatase value in current studies suggestive to damage to mucosal cells of intestine due to parasitic pathogenesis in GIT disorders.

\section{Conclusion}

Parasitological findings revealed strongyle followed by Strongyloides spp. and Moniezia spp. Hematological studies evidenced that significantly decreased values of $\mathrm{Hb}, \mathrm{PCV}$ and TEC. Absolute leukocytic count revealed significant leukocytosis due to neutrophilia, lymphocytosis, monocytosis and eosinophilia. There was no significant change in ESR. Serum biochemical profiles of diarrheic sheep/lambs in present study were significant decrease in values of TP, serum globulin, glucose whereas significant increase in the albumin: Globulin ratio, AST, ALT, ALKP and bilirubin.

\section{Authors' Contributions}

SK, KKJ and SSG have designed the study and planned the research experiments. SK performed the research experiments. SP, KK and MP help in conducting experiment. All authors read and approved the final manuscript.

\section{Acknowledgments}

The authors are highly thankful to Dean, College of Veterinary Science and Animal Husbandry, LLR University of Veterinary and Animal Sciences, Hisar, India for providing necessary funds and facilities to carry out the investigation. 


\section{Competing Interests} interests.

The authors declare that they have no competing

\section{References}

1. National Dairy Development Board. Share of Agriculture and Livestock's Sector in Gross Domestic Products. Available from: http://www.nddb/org/. Last assessed on 20/08/2014.

2. Department of Animal Husbandry and Dairying, Haryana. Available from: http://www.pashudhanharyana.gov.in/. Last assessed on 20/08/2014.

3. Food and Agriculture Organization of The United Nations, 2010. Available from: http://www.faostat.fao.org/. Last assessed on 20/08/2014.

4. Anonymus (2012) 19th Livestock Census: All India Summary Report 2012. Department of Animal Husbandry, Ministry of Agriculture, Government of India.

5. Anonymus (1977) Manual of Veterinary Parasitological Laboratory Techniques. Ministry of Agriculture, Fishries and Food, Her Majesty's Stationary Office. Bulletin No. 18, London. p5-50.

6. Benjamin, M.M. (2008) Outline of Veterinary Clinical Pathology. $3^{\text {rd }}$ ed. Reprint. The Iowa State University, Press Ames, Iowa, U.S.A. Assessed on 28/01/2013.

7. Anonymous (1990) Operating Manual of RA-50 Chemistry Analyser. Miles Diagnostic India Limited, India.

8. Kumar, S., Jakhar, K.K., Mishra, S.K. and Purohit, B.S.R. (2013) Pathology of digestive and respiratory tracts disorders in sheep. Indian J. Vet. Pathol., 37(2): 124-127.

9. Gaurav. and Jakhar K.K. (2011) Etio-pathological studies on gastrointestinal tract disorders in sheep and goat. Indian J. Vet. Pathol., 35: 116.

10. Mederos, A. Fernándezb, S., VanLeeuwenc, J., Peregrineb, A.S., Keltona, D., Menziesa, P., LeBoeufd, A. and Martine, R. (2010) Prevalence and distribution of gastrointestinal nematodes on 32 organic and conventional commercial farms in Ontario and Quebec, Canada (20062008). Vet. Parasitol., 170(3-4): 244-252.

11. Lashari, M.H. and Tasawar Z. (2011) Prevalence of some gastrointestinal parasites in sheep in Southern Panjab, Pakistan. Pak. Vet. J., 31(4): 295-298.

12. Gadahi, J.A., Arshed, M.J., Ali, Q., Javaid, S.B. and Shah, S.I. (2009) Prevalence of Gastrointestinal parasites of sheep and Goat in and around Rawalpindi and Islamabad, Pakistan. Vet. World, 2(2): 51-53.

13. Bordoloi G., Jas R. and Ghosh J.D. (2012) Changes in the haemato-biochemical pattern due to experimentally induced haemonchosis in Sahabadi sheep. J. Parasitol. Dis., 36(1): 101-105.

14. Dhanlakshmi, H., Jagannath, M.S. and D'Souza, P.E. (2002) Haematological and gamma globulin changes in sheep naturally infected with strongyles. Indian J. Anim. Sci., 72(12): 1094-1095.

15. Zaki, M.S., El-Shenawy, A. and El-Khateeb, R.M. (2003) Some studies on sheep naturally infested with Haemonchus contortus and some methods of treatment. Bull. Nat. Res. Cent. Cairo, 28(1): 63-71.

16. Purohit, K., Bhowmik, M.K., Roy, S., Singh, A.S. and Mukhopadhayay S.K. (2003) Some biochemical studies on Garole sheep infected with amphistome parasites. Indian J. Anim. Sci., 73(10): 1120-1122.

17. Misra, R.C., Panda, D.N. and Parida, S. (1996) Haematological and histological alteration of immature paramphistomiasis in lambs. Indian Vet. J., 73(12): 1274-1276.

18. Maiti, S.K., Rao, V.N., Pal, S. and Ali, S.L. (1999) Clinicohaematological and therapeutic studies in parasitic gastroenteritis in sheep. Indian Vet. J., 76(5): 435-437.

19. Pandit S., Jas R., Ghosh, J.D. and Moi, S. (2009) Impact of naturally occurring gastrointestinal nematodosis on serum protein concentration in Garole sheep. Environ. Ecol., 27(4): 1526-1529.

20. Qamar, M.F. and Maqbool A. (2012) Biochemical studies and serodiagnosis of haemonchosis in sheep and goats. $J$. Anim. Plant Sci., 22(1): 32-38.

21. Radostits, O.M., Gay, C.C., Hinchkliff, K.W. and Constable, P.D. (2007) Veterinary Medicine. 10th ed. Bailliere Tindall, London.

22. Prasanthi, B., Choudhuri, P. C. and Syaamsunder N. (1999) Biochemical observations in ovine Strongylosis. Indian Vet. J., 76(10): 892-894.

$* * * * * * * *$ 